\title{
Rede Afetiva do Design Universal para Aprendizagem na Educação 2.0: Reflexões e Possibilidades
}

\author{
Danielli Veiga Carneiro Sondermann ${ }^{1,2}$, Hiran Pinel ${ }^{1}$, Isaura Alcina Martins \\ Nobre $^{1,2}$ \\ ${ }^{1}$ Universidade Federal do Espírito Santo - UFES, Av. Fernando Ferrari, 514, Goiabeiras \\ Vitória - ES - CEP 29075-910 \\ ${ }^{2}$ Instituto Federal do Espírito Santo - Ifes , Campus Serra. Rod. ES 010, s/n \\ Manguinhos - Serra - ES. Cep: 29164-231 \\ danielli@ifes.edu.br, hiranpinel@ig.com.br, isaura@ifes.edu.br
}

\begin{abstract}
This paper presents some reflections on the Affective Network proposed by the Universal Design for Learning from a course offered in distance mode offered in a graduate school in the area of Technology and Education for a public university. The Affective Network is related to interest and things that challenge us, tends to get a plan to the "why" of learning activities and ideas that motivate learning. It is proposed to present some thoughts and possibilities for offering courses in the distance education in times of Education 2.0, that is, construction of knowledge through Web 2.0.

Resumo. Este artigo apresenta algumas reflexões em torno da Rede Afetiva proposta pelo Design Universal para Aprendizagem a partir de uma disciplina ofertada na modalidade a distância oferecida em uma pósgraduação na área de Tecnologia e Educação por uma instituição pública de ensino. A Rede Afetiva está relacionada ao interesse e as coisas que nos desafiam, tende a buscar um planejamento voltado ao "por que" de aprendizagem, das atividades e das ideias que motivam a aprendizagem. Este se propõe a apresentar algumas possibilidades e desafios enfrentados na oferta de disciplinas na modalidade a distância em tempos de Educação 2.0, ou seja, construção de conhecimento por meio da Web 2.0.
\end{abstract}

\section{Introdução}

Ao pensarmos em Educação 2.0, ou seja, no uso das Tecnologias de Informação e Comunicação (TICs) na Educação temos vários recursos, tais como: ferramentas voltadas para a colaboração, o uso de redes sociais e de mídias em geral; planejados para o processo de ensino e de aprendizagem, independente da modalidade de ensino.

Nesse universo sobre o uso das tecnologias na educação, destacamos a importância do trabalho de designer instrucional, lembrando que este tem recebido diversas denominações ao longo dos anos: desenhista educacional, projetista educacional, desenhista instrucional etc. "O termo de design instrucional refere-se ao processo sistemático e reflexivo de traduzir princípios de aprendizagem e instrução em planos de materiais didáticos, atividades, recursos, informação e avaliação (SMITH et al, 2005, p. 4)". Outra denominação é a de design pedagógico: 
[...] o design pedagógico propõe a integração de fatores técnicos, gráficos e pedagógicos, de modo a possibilitar ao usuário uma ação autônoma e investigativa. Verifica-se que a simples comunicação de um conceito não é suficiente para a construção de uma aprendizagem significativa (BEHAR, TORREZZAN, p. 23, 2009).

No Brasil, o profissional designer instrucional teve a regulamentação da profissão em 2009, pela Classificação Brasileira de Ocupações (CBO). O reconhecimento desse profissional se deu graças ao crescimento da Educação a Distância (EaD), entretanto, este profissional é muito importante ao pensarmos no uso de tecnologias como apoio ao processo de ensino e de aprendizagem, seja para a $\mathrm{EaD}$ ou para a modalidade presencial.

Além disso, nos últimos anos muitas têm sido as políticas públicas favorecendo a Educação Especial e a Educação Inclusiva visando à participação dos alunos com deficiência no ensino regular e que vêm favorecendo o ingresso desses alunos no ensino superior e muitas universidades encontram-se despreparadas para receber esse público. É preciso garantir o acesso, a permanência e a qualidade no ensino oferecido. Tal fato só reforça a importância do profissional de designer instrucional no planejamento de atividades que se adequem a favorecer a aprendizagem também deste tipo de aluno. Sendo assim, apostas no Design Universal para Aprendizagem (DUA), também conhecido como Design Instrucional Universal (DIU) se fazem necessárias, pois possibilita que alunos com necessidades especiais tenham condições equitativas no processo de ensino e de aprendizagem.

O DUA também atende aos diferentes estilos de aprendizagem, independente da questão da deficiência. O termo Design Universal para Aprendizagem foi adotado pela Center for Applied Special Technology (CAST) - Centro de Tecnologia Especial Aplicada e divulgado pelo National Center on Universal Design for Learning (UDL Center) - Centro Nacional de Design Universal para Aprendizagem.

Os pesquisadores da CAST (2012) identificaram três áreas principais ou 'redes' no DUA:

- Rede de conhecimento: lugar onde se processa as informações obtidas por nossos sentidos, por exemplo: textos lidos e/ou ouvidos, imagens vistas e/ou objeto que tocamos. Esta rede é formada pelas informações que chegam até o cérebro e representa "O quê" da aprendizagem.

- Rede Estratégica: responsável pelo auxílio na organização das ideias e, em seguida, pelo planejamento e realização as atividades propostas. Ao responder algo, utiliza-se a rede estratégica. É o "como" da aprendizagem.

- Rede Afetiva: relacionada ao interesse e as coisas que nos desafiam. A rede afetiva é o "por que" de aprendizagem, das atividades e das ideias que motivam a aprendizagem. Aprender um conceito de matemática para conseguir êxito em algum jogo seria um exemplo relacionado à rede afetiva.

As redes propostas pelo DUA se entrecruzam, Pozo (2005, p. 110) nos diz que "[...] não há cognição sem emoção" e essa afirmação reforça a importância de nossa preocupação com relação à afetividade no processo educacional, inclusive na Educação 2.0. Com as tecnologias disponíveis é possível uma maior interação com os alunos, como por exemplo, os Ambiente Virtuais de Aprendizagem (AVA), as Redes Sociais, as 
ferramentas de WebConferência dentre outras. Palloff e Pratt (2002) chamavam atenção sobre a predominância dos textos em tela como forma de comunicação na $\mathrm{EaD}$, como fator determinante para dificultar os vínculos afetivos, devido a impossibilidade de demonstrar expressão facial e linguagem corporal, ouvir vozes e a emoção presente em sua entonação. Essa questão vem sido superada por algumas das tecnologias citadas que permitem a comunicação síncrona (tempo real) por meio do uso de imagens e sons.

Outra questão relacionada à $\mathrm{EaD}$ é sobre o planejamento, nos cursos ofertados na modalidade a distância, na instituição pesquisada é comum ouvirmos falas sobre um possível 'engessamento da Educação a Distância (EaD)' devido ao planejamento sistemático antecipado de todo o conteúdo, incluindo atividades e recursos midiáticos. Entretanto, muitas intervenções podem ocorrer ao longo da oferta de uma disciplina, seja pela inclusão de materiais complementares, propostas de construção colaborativas, novas estratégias de ensino inseridas e uso de ferramentas síncronas para discussão sobre temáticas mais complexas.

Esse artigo tem como objetivo apresentar uma análise realizada sobre a Rede Afetiva proposta pelo Design Universal para Aprendizagem, pouco difundida no Brasil, por meio de reflexões e possibilidades tendo como contexto para a realização da pesquisa a oferta de uma disciplina ofertada na modalidade a distância de um curso de pós-graduação lato sensu na área de Tecnologia e Educação oferecida por uma instituição pública de ensino.

\section{Afetividade e o Processo Educativo}

Muitos autores discutiram sobre a importância da afetividade no processo educativo em diferentes contextos, dentre eles Piaget, Vygotsky e Wallon.

Piaget reconheceu que a afetividade é um agente motivador para a atividade cognitiva, que na proposta do Design Universal para Aprendizagem é desenvolvido pela Rede Estratégica. "A afetividade seria a energia, o que move a ação, enquanto a razão seria o que possibilitaria ao sujeito identificar desejos, sentimentos variados, e obter êxito nas ações (PIAGET, 1992, p. 76)". Nessa perspectiva, a afetividade está mais relacionada ao aspecto da motivação individual como potencializadora para o processo educativo.

Vygotsky também reconheceu que os processos pelos quais o afeto e o intelecto se desenvolvem estão interrelacionados e sofrem influências mútuas (OLIVEIRA, 1992).

Wallon (2007) se aprofundou na questão sobre afetividade defendendo que a inteligência não é o principal componente para o desenvolvimento, sendo este formado em três dimensões: motora, afetiva e cognitiva. $\mathrm{O}$ autor destaca que a inteligência cumpre a função de orientar, descobrir, explicar e transformar o mundo externo sejam os seres e as coisas. Enquanto a afetividade está relacionada às pré-disposições internas, motivações e envolvimento que nos afetam em relação ao outro e ao mundo material concreto.

Percebemos que a afetividade é inserida como uma das redes do design universal para aprendizagem, por sua importância no processo de ensino e aprendizagem. Tal processo não deve se restringir apenas às questões cognitivas, pois a forma como os alunos são motivados para aprender representa um elemento crucial. Dentro desse 
contexto a Educação 2.0, abre espaços, tanto para a modalidade a distância quanto presencial, pela possibilidade do uso da tecnologia como mais uma forma de motivação para a aprendizagem, seja pela forma como o conteúdo pode ser apresentado seja pela possibilidade de mediação, de interação entre professor-aluno e aluno-aluno.

Quando pensamos em afetividade no âmbito educacional devemos reconhecer um professor que se preocupa com as diversas interações que ocorrem em uma 'sala de aula', seja ela presencial ou virtual, por demonstrarem comportamentos, intenções, valores, crenças e sentimentos que podem afetar o processo de aprendizagem.

Em nossa vivência na Educação a Distância, certo dia, ouvimos de um professor: "Olha, eu preparo as disciplinas sem problemas, mas não me peçam para ser tutor, esse negócio de todo dia enviar mensagem de motivação para o aluno individualmente, não é para mim". Outra fala, vinda de uma tutora foi "Eu sou tutora e não babá de aluno, para ficar lembrando a todo o momento que ele tem que cumprir os prazos de maneira adequada". Essas falas nos fazem refletir sobre a falta de conhecimento em torno da afetividade e que implicações podem gerar. A linguagem utilizada no material textual, os feedbacks dados aos alunos, as estratégias de ensino propostas e as mídias utilizadas, todas de alguma forma estão relacionadas à questão da Rede Afetiva.

\section{O Planejamento da Rede Afetiva}

Vários fatores estimulam a motivação do aluno para aprender, desde questões culturais, relevância pessoal, subjetividade, base de conhecimento dentre outras. Alguns alunos são motivados de maneira espontânea e/ou pela novidade, enquanto outros alunos são mais distantes e/ou apresentam certo medo com relação ao novo conhecimento. Eis um dos grandes desafios para o profissional, designer instrucional, que desenvolve $o$ planejamento do Design Universal para Aprendizagem, fica a questão: Como planejar a Rede Afetiva?

A motivação também está relacionada às estratégias de ensino adotadas pelo professor, alguns gostam de debates em grupo, outros insistem na aula expositiva como sendo a melhor forma de aprendizagem. Alguns alunos preferem trabalhar sozinhos ao invés de em grupos. Diante desse quadro, temos que ter consciência que não existe um método de ensino que agrade a todos os alunos, mas devemos buscar formas de minimizar essa questão tão importante ao processo educativo.

As aprendizagens de determinadas ações e/ou conteúdos podem exigir muito esforço e atenção, dificilmente um aluno sem motivação conseguirá dedicar-se de maneira adequada e no tempo estimado. É preciso propor uma variedade nos métodos utilizados de forma a propor alternativas aos alunos com habilidades e estilos de aprendizagem diferenciados.

Algumas questões sobre o planejamento da Rede Afetiva, de uma dada disciplina e/ou curso, no DUA (CAST, 2012):

- Conhecer sobre o planejamento e a oferta da disciplina anteriormente, caso haja.

- Fazer com que os alunos compreendam os objetivos propostos e façam uma autoavaliação sobre o seu entendimento e evolução. 
- Realizar exemplos que se conectem ao seu contexto cultural e aos seus interesses pessoais e/ou profissionais.

- Permitir nova realização das atividades propostas, baseada na auto-reflexão do aluno mediado pelo professor.

Outras questões estão relacionadas à Rede Afetiva para além do planejamento, dentre elas: a infraestrutura disponível para a realização do curso, a linguagem utilizada nos feedbacks e interações dados pelos professores durante a oferta da disciplina, o tempo de resposta, a motivação pessoal e o relacionamento com a turma.

Como forma de procurar responder a questão "Como planejar a rede afetiva?" apresentamos o Modelo ADDIE (INTULOGY, 2012), um dos modelos de design instrucional que mais tem sido utilizado nos planejamentos de cursos a distância, consiste em cinco fases: (1) Analysis - Análise, (2) Design - Projeto, (3) Development Desenvolvimento, (4) Implementation - Implementação e (5) Evaluation - Avaliação. A seguir apresentamos cada fase resumidamente:

- Análise: nesta fase o designer instrucional identifica o contexto da aprendizagem, o público-alvo, as metas e os objetivos, dentre outras características relevantes. Nessa fase também devemos conhecer a instituição, implicações sobre o ambiente, recursos disponíveis (financeiro, infraestrutura, recursos humanos) e prazos.

- Projeto: construímos de maneira sistemática os objetivos da aprendizagem, detalhando conteúdos e atividades. É nessa fase que também definimos as mídias que serão utilizadas, necessitando muitas vezes a criação de storyboards (detalhamento tela a tela de um vídeo e/ou animação), projetos de interface e/ou de navegação.

- Desenvolvimento: nesta fase é que efetivamente ocorre a produção dos materiais planejados na fase anterior, dependendo da instituição existe uma equipe só para essa demanda.

- Implementação: esta fase é responsável pelos testes de validação do material e a implantação do material produzido.

- Avaliação: temos a avaliação formativa que está presente a cada fase do Modelo ADDIE e a avaliação somativa que consiste em testes aplicados aos usuários do material produzido. Revisões podem ser necessárias durante essa fase.

- As fases apresentadas apesar de apresentarem uma estrutura linear são comuns retornarmos a uma das fases, realizarem as mudanças necessárias e alterando as fases atingidas pela mudança.

Podemos observar que é na fase de Análise do modelo que os objetivos são redigidos e, portanto, é nela que o planejamento da Rede Afetiva deve ser iniciado. Nessa fase e considerando a Taxonomia de Bloom (FERRAZ; BELHOT, 2010) para a escrita dos objetivos relacionados a parte afetiva, estes deveriam estar relacionados aos sentimentos e as posturas desejadas. Sendo assim, apresentamos uma proposta para o planejamento da Rede Afetiva, por meio das categorias do domínio afetivo proposto por Bloom e seus colaboradores:

- Receptividade: Relacionado à linguagem utilizada para a exposição dos conteúdos, que dever ser atrativa e acessível a todos os alunos. 
- Resposta: Proposição de atividades motivadoras em que o aluno possa demonstrar o seu entendimento sobre o conteúdo abordado.

- Valorização: Proposição de atividades em que o aluno possa atribuir seu valor com relação ao tema discutido por meio de reconhecimento, participação e decisão.

- Organização: Criação de atividades com um nível mais elevado e em grupo, onde o aluno possa organizar relacionar e julgar de acordo com a sua abordagem teórica.

- Caracterização: Criação de condições para que o aluno possa ser destacado em sua comunidade escolar. Esse é o nível mais alto da taxonomia.

Dessa forma, as demais fases do Modelo ADDIE deverão contemplar os objetivos afetivos traçados na fase de análise.

\section{Contexto da Pesquisa}

A pesquisa foi realizada com alunos do curso de pós-graduação Lato Sensu na área de Tecnologia e Educação, voltado para o planejamento e uso de tecnologias na educação em seus diferentes níveis e modalidades de ensino, oferecido por uma instituição pública de ensino por meio do seu Centro de Educação a Distância (Cead) e a análise foi feita sobre a ótica do Design Universal para Aprendizagem, com foco na Rede Afetiva.

A oferta da disciplina foi realizada em Fevereiro/2012 a Abril/2012. A turma era composta por 178 alunos, distribuídos em cinco polos de apoio presencial, alguns mais próximos da capital e outros mais distantes, localizados no interior do estado. A partir dos dados coletados sobre o perfil dos alunos ingressantes ao curso, pudemos perceber que a maioria dos alunos era feminina (67\%) e com idade acima dos 30 anos (73\%). Três alunos possuem deficiência visual e um aluno possui deficiência auditiva. 55\% dos alunos já possuem um curso de pós-graduação completo. A maioria dos alunos é licenciada (45\%) ou pedagogos (38\%), o restante possuem outro tipo de graduação, sendo que $8 \%$ são da área de Informática. Dado o perfil do curso e dos alunos, em sua maioria professores do ensino fundamental e médio da rede pública, entendemos que estes buscam por meio desse curso aprender a utilizar os recursos tecnológicos em sua prática docente.

A disciplina escolhida para a realização da pesquisa foi Produção de Material Digital, cujo objetivo é discutir sobre as diversas mídias relacionando-as com as diferentes teorias de aprendizagem e a utilizar algumas ferramentas para a criação de materiais digitais, e também reconhecer alguns aspectos sobre direitos autorais. A disciplina possui uma carga horária de 40 horas e foi organizada em sete semanas. Concomitantemente a esta, tivemos a oferta da disciplina de Mapas Conceituais.

Dado o grande número de alunos matriculados na disciplina os alunos são alocados no Ambiente Virtual de Aprendizagem (AVA), no caso o Moodle (MOODLE, 2012), em grupos referentes aos seus polos de apoio presencial. Cada grupo/polo tem o apoio de um professor-tutor para cada 25 alunos. Essa é uma estratégia que permite maior acompanhamento das discussões por parte dos professores-tutores e também tende a deixar os alunos mais à vontade, uma vez que interagem apenas com os seus colegas de polo. Por outro lado, impede a interação de alunos nos outros grupos/polos. Assim, os professores são orientados a compartilhar as postagens interessantes que acontecem em determinado polo com os demais. 
O restante da organização da sala é distribuído em semanas, com: uma agenda, leituras e atividades acompanhadas ou não de vídeos, tutoriais e animações. Ao final de cada semana há um Fórum de Dúvidas. Os alunos são estimulados a utilizá-lo, assim ao responder a dúvida de um aluno, a mesma pode ser aproveitada pelos demais colegas do grupo.

Como pudemos observar as questões relacionadas à Rede Afetiva estão inseridas implicitamente no planejamento de uma disciplina na modalidade a distância. Ela pode aparecer por meio da linguagem utilizada no material textual, nos enunciados das atividades propostas, nas interações entre o professor-tutor / aluno e aluno / aluno. Dessa forma, é preciso pensar estratégias de ensino que se conectem com a Rede Afetiva, gerando uma maior motivação e entendimento sobre o porquê da aprendizagem.

Segundo Lévy uma comunidade virtual: “[...] é construída sobre as afinidades de interesses, de conhecimentos, sobre projetos mútuos, em um processo de cooperação ou de troca, tudo isso independentemente das proximidades geográficas e das filiações institucionais" (1999, p.127).

No sentido de diminuir as distâncias transacionais entre professor-aluno e alunoaluno buscando ainda mais estreitar as relações sociais e o compartilhar de interesses e de conhecimentos, durante a oferta da disciplina foi criado um grupo no Facebook com o intuito de verificar o uso de uma rede social em conjunto com um Ambiente Virtual de Aprendizagem, no caso o Moodle. A participação no Facebook não foi obrigatória e o convite foi feito no intuito de termos um espaço de discussão para além da oferta da disciplina. Sendo assim, dos 178 alunos tivemos um total de 105 membros inscritos no grupo.

\section{Reflexões em torno da Rede Afetiva}

Antes de iniciar o planejamento da disciplina, tivemos uma reunião com o designer instrucional do curso e uma discussão sobre a disciplina ofertada anteriormente e alguns pontos foram identificados e que estão relacionados com a Rede Afetiva. Alguns comentários obtidos por meio da avaliação da disciplina anterior: "Tutor se comunicava de forma muito concisa" e "Tutor menosprezava as dificuldades dos alunos". Também identificamos crítica com relação a prova de cunho teórico para uma disciplina que tem grande ênfase ao atendimento de objetivos práticos como, por exemplo, a criação de um material digital.

Outro ponto que chamou atenção e que reforça a proposta do Design Universal para Aprendizagem foi o tempo de dedicação semanal à disciplina, variando de 0 a 5 horas para até mais de 20 horas semanais, ou seja, cada aluno possui um ritmo diferenciado no que diz respeito ao processo de ensino e de aprendizagem.

Também não identificamos atividades que potencializassem de maneira direta o entendimento sobre os objetivos propostos. Por exemplo, uma das atividades tinha o seguinte enunciado: "Publique na Internet o material digital produzido na Tarefa 2. Crie neste fórum um tópico com o seu nome, informando: o endereço do conteúdo publicado. Opcionalmente, descreva também os passos realizados para conseguir a publicação e/ou as dificuldades encontradas durante esse processo". Apesar do termo opcionalmente, a 
maioria dos alunos descreveram sobre as dificuldades encontradas e forma de superação das mesmas. Algumas falas:

"Não achei a tarefa simples. Como a maioria das páginas que oferecem este tipo de serviço estão em inglês, foi necessário dispensar mais tempo e paciência e, claro, contar com a ajuda dos colegas" - Aluna A.

"Desenvolver esta tarefa foi muito emocionante, pois adoro fazer este tipo de tarefa. Não tive dificuldades pois já trabalho com html" Aluno B.

"O mais dificil foi fazer o site, não entendi muito bem! nem com as explicaçãoes escritas do tutor eu consegui fazer sozinha, pedi ajuda as universitárias... acredito que é importante ver o que se passa nos bastidores de um site, mas também necessitamos de um suporte maior e mais adequado as nossas dúvidas..." - Aluna $\mathrm{C}$.

As demais atividades que não continham nada no enunciado sobre comentários sobre o processo de realização das atividades propostas, foram realizadas de maneira operacional, distanciando o professor-tutor sobre as dificuldades encontradas e formas de superá-las. Aqui cabe uma primeira reflexão: É preciso deixar claro nos enunciados sobre a atividade proposta e a realização de uma autoavaliação sobre o desenvolvimento da mesma. Dessa forma é possível levar o aluno a refletir sobre o processo desenvolvido na solução das atividades propostas fazendo com que o mesmo tome consciência sobre a sua aprendizagem.

Em uma disciplina ofertada na modalidade a distância, com alunos distribuídos em cinco polos com características regionais diversas e interesses pessoais / profissionais também diversos, sabemos da complexidade em realizar atividades que se conectem ao contexto cultural e interessses individuais. Na avaliação realizada na oferta da disciplina, uma fala reforça esta questão: "Foram utilizados muitos termos técnico, não comum a vida dos alunos".

No início da disciplina a professora formadora incentivou os tutores a corrigirem as atividades assim que fossem postadas e, caso fosse necessário, deixarem o aluno melhorá-la. Entretanto, a comunicação sobre esta questão não ficou clara para todos os alunos; e os alunos que deixaram para o prazo final se sentiram prejudicados. Apesar das exigências legais em torno de um calendário letivo faz-se necessário flexibilizar os prazos, desde que os alunos demonstrem motivação e não vire uma prática rotineira.

Com relação à análise do uso da Rede Social, pudemos perceber o quanto os alunos sentiam-se livres e motivados, sem o rigor da escrita acadêmica exposto culturalmente nos Ambientes Virtuais de Aprendizagem. É como se o AVA fosse uma 'sala de aula tradicional', onde assunto fora do conteúdo proposto não pudesse ser abordado. Esta é uma importante reflexão em torno da Rede Afetiva e que pode ser observada no recorte feito a partir do Facebook.

"Aff, estouu enlouquecendo com as atividades de HTML, loucura, loucura......

Tentei, tentei, tentei, inumeras vezes resolver o problema do meu video q nao esta funcionando, mas o meu amiguinho não quer funcionar por nada nesse mundoooooo, kkkkkkkkkkkkkkkkkkkkk...Vou dormir, pq o sonoo hj veio $\mathrm{q}$ veio contudoooo..... 
ZZZZZZZZZZZZZZZZZZZZZZZZZZZZZZZZZZZZZZZZZZZZZZZZZZZZZZZZZZZZZZZZZ zzzzzzzzzzzzzzzzzzzzzz" - Aluna A.

"desisti da tarefa" - Aluna B.

“Oi aluna-2, eu não desisti, não mas já tive a nota da primeira postagem sobre html e não foi nada positiva, pois não abriu os aplicativos . Estou aguardando as outras. Mas isso não é para ser despejado em cima da gente assim não. Mesmo especialistas estão pasmos , pela falta de informações que nos foi passada" - Aluna C.

"Tbm concordo o material esta muito complexo, acho q poderia ser + detalhado, pois a maioria dos alunos nunca tiveram contato com essas ferramentass....." - Aluna A.

Com base nas falas observamos a desmotivação da Aluna B ao desistir da tarefa e a perseverança e esforço da Aluna $\mathrm{C}$ na superação do desafio. Evidencia-se que na rede social o aluno se sente mais a vontade para expressar suas emoções, valores e crenças. Fica claro a necessidade do acompanhamento sistemático pelo professor dessas redes de relações e que este intervenha sempre que identificar que algum conteúdo esteja sendo considerado complexo, o que observamos na sala, foi a sugestão de novos materiais complementares e um esforço dos tutores em auxiliar os alunos com dificuldade.

\section{Considerações Finais}

Nesse artigo pudemos observar a importância de se estabelecer a Rede Afetiva independente da modalidade de ensino. É fato que o ensino presencial nos permite um contato direto por meio das expressões, de gestos e de falas, mas na modalidade a distância podemos observar os alunos, por meio de suas escritas, de suas participações nos momentos síncronos e pela realização das suas atividades.

Conhecer a oferta anterior minimiza alguns problemas, mas temos consciência que cada turma pode apresentar novos problemas e/ou soluções para melhorar o processo de ensino e de aprendizagem. É preciso envolver mais os alunos com relação ao conhecimento dos objetivos propostos, para que os mesmos consigam refletir sobre sua evolução e motivação.

Em se tratando da Educação a Distância, que normalmente possui um grande número de alunos distribuídos entre diferentes municípios é difícil estabelecer exemplos que se conectem ao seu contexto cultural e aos seus interesses pessoais / profissionais, mas temos que encontrar pontos em comum para criar conteúdos, atividades e mídias que realmente fomentem a motivação em realizá-las.

Oportunizar ao aluno novas oportunidades deve ser a base para estabelecer a Rede Afetiva, não apenas no sentido de deixar realizar a atividade novamente, mas criar meios para que o aluno reflita sobre os motivos que o levaram a não realizar a atividade e que caminhos são possíveis para concluí-la.

A concepção de uma Rede Afetiva, além da concepção das redes de conhecimento e estratégia, leva a um planejamento de design instrucional da disciplina, seja ela presencial ou a distância, que contemple atividades motivadoras e as interações necessárias para o desenvolvimento do aluno e do professor. 


\section{Referências Bibliográficas}

BEHAR, P. A.; TORREZZAN, C. A. W (2009). Metas do design pedagógico: um olhar na construção de materiais educacionais digitais. Revista Brasileira de Informática na Educação, Vol. 17, $\quad \mathrm{n}^{\mathrm{o}} \quad 3, \quad$ p.11-24. $\quad$ http://www.brie.org/pub/index.php/rbie/article/view/1023/1015. Julho.

CAST (2012). Center for Applied Special Technology. http://www.cast.org/. Maio.

FERRAZ, A. P. C. M; BELHOT, R. V (2010). Taxonomia de Bloom: revisão teórica e apresentação das adequações do instrumento para definição de objetivos instrucionais. Revista Gestão \& Produção, v.17, n. 2, p. 421-431. http://www.scielo.br/pdf/gp/v17n2/a15v17n2.pdf. Maio.

INTULOGY (2012). The ADDIE instructional design model: a structured training methodology. http://www.intulogy.com/addie/index.html. Maio.

LÉVY, P (1999). Cibercultura. Editora 34, São Paulo.

MOODLE (2012). http://moodle.org/about/. Maio.

OLIVEIRA, M. K (1992). O problema da afetividade em Vygostsky. In: LA TAILLE, Y. (Org.) Piaget, Vygotsky, Wallon: teorias psicogenéticas em discussão. Summus, São Paulo, p. 75-84.

PALLOFF, R. M e PRATT, K (2002). Construindo comunidades de aprendizagem. Trad. Vinícius Figueira, Porto Alegre, Editora ARTMED.

POZO, J. I (2005). Aquisição de conhecimento. Artmed, Porto Alegre.

SMITH, P., TILMANN, J. R (2005). Instructional Design. $3^{\text {a }}$ edição. Wiley Jossey Bass Education, EUA.

UDL Center (2012). National center on universal design for learning. http://www.udlcenter.org/. Maio.

WALLON, H (2007). A evolução psicológica da criança. Martins Fontes, São Paulo.

INTULOGY (2012). The ADDIE instructional design model: a structured training methodology. http://www.intulogy.com/addie/index.html. Maio. 